\title{
Journal of Experimental Food
}

\section{Environmental Alarm}

\section{Amal M Metak ${ }^{*}$}

School of Science and Engineering, Teesside University, UK

"Correspondence author: Metak AM, School of Science and Engineering, Teesside University, Borogh Road, Middlesbrough, TS1 3BA, UK, Tel: 01642-342458; Fax: 01642342401; E-mail: A.Metak@tees.ac.uk

Received date: Nov 3, 2015; Accepted date: Nov 9, 2015; Published date: Nov 16, 2015

Copyright: @ 2015 Metak AM. This is an open-access article distributed under the terms of the Creative Commons Attribution License, which permits unrestricted use, distribution, and reproduction in any medium, provided the original author and source are credited.

\section{Editorial}

The use of engineering nanoparticles (ENPs) has developed rapidly over the last decade, mainly due to concern for the environment and a lack of resources.

The numbers of consumer products containing ENPs are being increasingly used in cosmetics and personal care products, pharmaceutical and medical applications, catalysts, paints and coatings, construction materials, chemical and biological sensors, food processing and packaging, plastic, clothing and water treatment.

Silver nanoparticles (Ag-NPs) are currently the most-used ENPs in commercially available products. Products containing ENPs have the potential to release particles in the form of single entities or aggregates or ions through waste-water discharge into the aquatic environment and it is argued that a significant environmental impact will occur from new applications of ENPs.

A major concern arises from the impact of ENPs on the sewage system; there is a wide gap between the proliferation of consumer products and research. There is also an imbalance between the manufacturing industry and the regulatory agencies. Several authors have recently reported the occurrence of Ag-NPs in surface water.

The rapid growth of utilization of ENPs in commercial products has raised questions about their long-term effects, bio-accumulation, and their impact on the environment and humans. 